KAPL-P-000214

(K99028)

\title{
AMORPHIZATION OF LAVES-PHASE PRECIPITATES IN ZIRCALOY 4 BY NEUTRON IRRADIATION
}

D. F. Taylor, H. R. Peters, et. al

August 1999

\section{NOTICE}

This report was prepared as an account of work sponsored by the United States Government. Neither the United States, nor the United States Department of Energy, nor any of their employees, nor any of their contractors, subcontractors, or their employees, makes any warranty, express or implied, or assumes any legal liability or responsibility for the accuracy, completeness or usefulness of any information, apparatus, product or process disclosed, or represents that its use would not infringe privately owned rights. 


\section{DISCLAIMER}

This report was prepared as an account of work sponsored by an agency of the United States Government. Neither the United States Government nor any agency thereof, nor any of their employees, make any warranty, express or implied, or assumes any legal liability or responsibility for the accuracy, completeness, or usefulness of any information, apparatus, product, or process disclosed, or represents that its use would not infringe privately owned rights. Reference herein to any specific commercial product, process, or service by trade name, trademark, manufacturer, or otherwise does not necessarily constitute or imply its endorsement, recommendation, or favoring by the United States Government or any agency thereof. The views and opinions of authors expressed herein do not necessarily state or reflect those of the United States Government or any agency thereof. 


\section{DISCLAIMER}

Portions of this document may be illegible in electronic image products. Images are produced from the best available original document. 


\title{
AMORPHIZATION OF LAVES-PHASE PRECIPITATES IN ZIRCALOY-4 BY NEUTRON IRRADIATION
}

Dale F. Taylor, H. Richard Peters, and Walter J.S. Yang

\author{
Lockheed Martin Corporation \\ P.O. Box 1072 \\ Schenectady, NY 12301-1072
}

\begin{abstract}
Examination of corrosion coupons by transmission electron microscopy after their exposure in the Idaho Advanced Test Reactor (ATR) has broadened the Zircaloy-4 precipitateamorphization database and validated a new kinetic model for previously unavailable values of temperature and fast-neutron flux. The model describes "the amorphization of $\mathrm{Zr}(\mathrm{Fe}, \mathrm{Cr})_{2}$ intermetallic precipitates in zirconium alloys as a dynamic competition between radiation damage and thermal annealing that leaves some iron atoms available for flux-assisted diffusion to the zirconium matrix. It predicts the width of the amorphous zone as a function of neutron flux ( $\mathrm{E}>1 \mathrm{MeV}$ ), temperature, and time. In its simplest form, the model treats the crystalline/amorphous and precipitate/matrix interfaces as parallel planes, and its accuracy decreases for small precipitates and high fluence as the amorphous-zone width approaches precipitate dimensions. The simplest form of the model also considers diffusion to be ratedetermining. This is an accurate approximation for steady-state conditions or slow changes in flux and temperature, but inappropriate for the analysis of faster transients. The paper addresses several difficulties inherent in measuring amorphouszone width, and utilizes the expanded database to evaluate the improvements in predictive accuracy available through both conversion of the model to spherical coordinates and extension of its time dependency.
\end{abstract}

\section{Introduction}

The dependence of corrosion rate upon the size, structure, and composition of intermetallic precipitates in nuclear fuel cladding remains the subject of active research. Initial reports of $\mathrm{Zr}(\mathrm{Fe}, \mathrm{Cr})_{2}$ amorphization by neutron irradiation and the concomitant loss of
Fe to the Zircaloy matrix immediately raised questions about possible contributions to the acceleration of post-transition uniform corrosion [1-3]. Garzarolli et al. established [4] (and later reiterated [5]) relationships between corrosion rate and initial precipitate size, and observed that the in-pile precipitate-size evolution changed from dissolution at temperatures below $290^{\circ} \mathrm{C}$ to ripening at temperatures above $340^{\circ} \mathrm{C}$ [6]. Motta and Lemaignan [7] analyzed tabular data from an earlier paper by Griffiths et al.[8] and presented graphical evidence that $\mathrm{Zr}(\mathrm{Fe}, \mathrm{Cr})_{2}$ amorphization in Zircaloy-4 peaked, then diminished rapidly as the temperature increased through the same interval. Both temperature dependencies matched the reversal of post-transition corrosion rate that Peters and Harlow observed for Zircaloy-4 corrosion coupons in the Advanced Test Reactor [9]. Yang noted that dissolution was much slower than amorphization [10], and Cheng et al. showed with tests in water and steam that prior neutron irradiation markedly accelerated the uniform corrosion of $\alpha$-annealed Zircaloy-4 without significantly changing the precipitate size distribution [11]. A direct dependence upon fluence, and transmission electron microscopy (TEM) studies of these and other materials, implicated an increase in alloyingelement solute concentrations as the accelerant.

Oxidation of aliovalent solute elements and their incorporation into the zirconia matrix should accelerate corrosion by increasing the ionic [12] and electronic [13] conductivities of the barrier layer. A narrow distribution of small precipitates requires fast $\beta$ quenching with minimal Ostwald ripening in the $\alpha$-phase field, a processing sequence that leaves the zirconium matrix with a high degree of solute supersaturation. Small precipitates also become amorphous more quickly than larger ones, and both characteristics are consistent with the inverse dependence of corrosion rate upon precipitate size that is typical of PWR's [4]. 
There is ample evidence for solute involvement in Zircaloy corrosion mechanisms, but experiments like the galvanostatic potential measurements in steam by Urquhart et al.[14], the potentiodynamic activation by Ito and Furuya [15], the demonstration of galvanic protection by Isobe et al. [16], and the micron-scale measurements of hydrogen distribution by Bossis et al. [17] add strong support for electronic and electrochemical contributions by the precipitates. Thus differences in electrical conductivity, hydrogen overpotential, and chemical reactivity between the crystalline core and the amorphous shell could manifest themselves as dependencies of the corrosion rate upon both initial precipitate size and reactor operating history.

Elucidation of the extent and mechanism of any contributions to the acceleration of post-transition uniform corrosion requires knowledge of both precipitate morphology and corrosion rate as a function of time, temperature, and neutron flux. In a previous paper [18], we introduced a quantitative model for the amorphization of $\mathrm{Zr}(\mathrm{Fe}, \mathrm{Cr})_{2}$ precipitates in Zircaloy-2 and Zircaloy-4 using data from Reference 8 . In this paper, we validate the model for Zircaloy-4 over wider ranges of flux and temperature, extend its predictions to the total amorphization of spherical precipitates, and improve its ability to predict transient behavior. Our purpose is to simplify ongoing mechanistic corrosion studies by providing a simple altemative to postirradiation measurements of amorphous-zone widths.

\section{Summary of the Equations}

The model postulates a homogeneous amorphous fraction $\alpha$ at the core/zone interface whose rate of change is the difference between the temperature-independent rate of amorphization by the neutron flux $\phi$ and the rate of thermal recrystallization [18]:

$$
\mathrm{d} \alpha / \mathrm{dt}=\mathrm{k}_{\phi}(1-\alpha) \phi-\mathrm{k}_{\chi} \alpha \exp \left(-\mathrm{E}^{*} / \mathrm{RT}\right)
$$

where $\mathrm{k}_{\phi}, \mathrm{k}_{\chi}$, and $\mathrm{E}^{*}$ are constants. When the system reaches steady state at constant $\mathrm{T}$ and $\phi, \mathrm{d} \alpha / \mathrm{dt}=0, \alpha=\alpha_{0}$, and

$$
\ln (\phi)=\ln \left(k_{\chi} / k_{\phi}\right)+\ln \left(\alpha_{0} /\left(1-\alpha_{0}\right)\right)-E^{*} / R T
$$

With assistance from the neutron flux, excited Fe atoms diffuse through the Fe-depleted amorphous zone from the core and accumulate in the matrix adjacent to the interface. Since Fe transport is proportional to the amorphous-zone growth rate, and the concentration gradient across the zone is small relative to the steep gradients at each interface,

$$
\mathrm{d} \delta / \mathrm{dt} \approx D \phi\left(\alpha_{0}-\beta \delta\right)
$$

when diffusion is slow relative to amorphization (steady-state approximation). Here, $\delta$ is the width of the amorphous zone, $D$ is a temperature-independent transport coefficient, and $\beta$ is a normalizing constant. Integration yields

$$
\delta=\left(\alpha_{0} / \beta\right)[1-\exp (-\beta D \phi t)]
$$

This is the model in its simplest form. From data in Reference 8, we estimated the constants to be

$$
\begin{array}{ll}
\mathrm{E}^{*} / \mathrm{R}=11,600\left({ }^{\circ} \mathrm{K}\right) & \ln \left(\mathrm{k}_{\chi} / \mathrm{k}_{\phi}\right)=51.7 \\
\beta=2.37 \times 10^{-3} \mathrm{~nm}^{-1} & \mathrm{D}=2.34 \times 10^{-20} \mathrm{~nm} \mathrm{~cm}^{2} \mathrm{n}^{-1}
\end{array}
$$

Equation 2 provides the dimensionless fractional value of $\alpha_{0}$ for constant $\phi\left(\mathrm{n} \mathrm{cm}^{-2} \mathrm{~s}^{-1}\right)$ and $\mathrm{T}\left({ }^{\circ} \mathrm{K}\right)$, and Equation 4 predicts the amorphous-zone width (nm) after time $\mathrm{t}(\mathrm{s})$.

\section{Extensions Of The Model}

\section{Time-Dependent $\alpha$}

For multiple intervals of short duration with step-changes in flux and temperature between intervals, it is more appropriate to retain the time dependence of $\alpha$ from Equation 1 for calculating cumulative changes in $\delta$. When the crystalline-to-amorphous transformation has started prior to a constant $[\phi, T]$ interval of length $t$, and $\alpha$ has a non-zero value ' $A$ ' at time 0 , the solution to Equations 1 and 2 is

$$
\alpha=\alpha_{0}-\left(\alpha_{0}-A\right) \exp \left(-k_{\phi} \phi t / \alpha_{0}\right)
$$

Changing $\alpha_{0}$ to $\alpha(t)$ in Equation 3 removes only the steady-state approximation:

$$
\mathrm{d} \delta / \mathrm{dt}=\mathrm{D} \phi(\alpha-\beta \delta)
$$

The derivatives with respect to time of Equations 5 and 6 combine to form the second-order linear differential equation

$$
d^{2} \delta / d t^{2}+(D \phi \beta) d \delta / d t=\left\{D \phi^{2}\left(\alpha_{o}-A\right) k_{\phi} / \alpha_{0}\right\} \exp \left(-k_{\phi} \phi t / \alpha_{o}\right)
$$

whose solution is

$$
\begin{aligned}
\delta=\frac{\alpha_{0}}{\beta} & +\frac{\alpha_{0} \beta D\left(A-\beta \delta_{0}\right)-k_{\phi}\left(\alpha_{0}-\beta \delta_{0}\right)}{\beta\left(k_{\phi}-\alpha_{0} \beta D\right)} \exp (-\beta D \phi t) \\
& +\underline{\alpha}_{0} D\left(\alpha_{0}-A\right) \exp \left(-k_{\phi} \phi t / \alpha_{0}\right)
\end{aligned}
$$

when $\delta_{o}$ is the width of the amorphous zone at time 0 . Using Equation 5, we estimated that

$$
\mathrm{k}_{\phi}=9.6 \times 10^{-22} \mathrm{~cm}^{2} \mathrm{n}^{-1}
$$

with a rather subjective analysis of time-dependent data in Reference 8 [18]. Note that sequential application of Equation 8 requires the simultaneous use of Equation 5 to provide ' $A$ ' for the next interval.

\section{One-Dimensional Spherical Coordinates}

Equation 3 assumes that the crystalline-amorphous and precipitate-matrix interfaces are parallel planes. The matrixconcentration (second) term uses the amorphous volume, $\delta$ per unit surface area, as a measure of the Fe that has moved from the crystalline core to the alloy matrix. For a spherical precipitate of radius ' $R$ ' with a crystalline core of radius ' $r$ ', the amorphous volume is $4 \pi\left(R^{3}-r^{3}\right) / 3, \delta$ is $(R-r)$, and the steady-state amorphization equation becomes

$$
\mathrm{dr} / \mathrm{dt}=-\mathrm{D} \phi\left\{\alpha_{0}-\mathrm{B}\left(\mathrm{R}^{3}-\mathrm{r}^{3}\right)\right\}
$$

where $\mathrm{B}$ is the new normalizing constant. This first-order nonlinear equation has an exact, if somewhat unwieldy, solution for time as a function of amorphization: 
$t=(\kappa / 6 a) \ln \left\{(\kappa+r)^{2} /\left(\kappa^{2}-\kappa r+r^{2}\right)\right\}+(\kappa / a \sqrt{ } 3) \tan ^{-1}\{(2 r-\kappa) /(\kappa \sqrt{ } 3)\}-(\kappa / 6 a) \ln \left\{(\kappa+R)^{2} /\left(\kappa^{2}-\kappa R+R^{2}\right)\right\}-(\kappa / a \sqrt{ } 3) \tan ^{-1}\{(2 R-\kappa) /(\kappa \sqrt{ } 3)\}$

where

$$
a=D \phi\left(B R^{3}-\alpha_{0}\right) \quad b=-D \phi B \quad k^{3}=\left(\alpha_{\alpha} / B\right)-R^{3}
$$

Equation 9 must approach Equation 3 as ' $r$ ' approaches ' $R$ '. For $\delta$ very small,

$$
\begin{gathered}
R^{3}-r^{3}=(R-r)\left(R^{2}+r R+r^{2}\right) \rightarrow(R-r)\left(3 R^{2}\right) \\
d \delta / d t \rightarrow D \phi\left\{\alpha_{0}-\beta(R-r)\right\} \quad d r / d t \rightarrow-D \phi\left\{\alpha_{0}-B(R-r) 3 R^{2}\right\}
\end{gathered}
$$

thus

$$
B=\beta / 3 R^{2}
$$

Substituting $\alpha(t)$ from Equation 5 for $\alpha_{0}$ in Equation 9 combines both extensions of the model, but the more complex first-order non-linear differential equation requires a numerical, or approximate polynomial, solution.

\section{Experimental}

\section{Materials}

This survey utilized results from examinations of eight Zircaloy-4 corrosion coupons dating back to 1982 . All source ingots had the same nominal composition, $\mathrm{Zr}-1.5 \mathrm{Sn}-0.2 \mathrm{Fe}-0.1 \mathrm{Cr}$ with $0.12-0.14$ weight-percent oxygen, and met the ASTM specifications for impurities. Normally, a final $650^{\circ} \mathrm{C}$ stress-relief anneal followed recrystallization in the high- $\alpha$ phase field at $780^{\circ} \mathrm{C}-790^{\circ} \mathrm{C}$. In one instance, a 30 -minute solutionizing heat treatment just above the $(\alpha+\beta+$ ppte $) /(\alpha+\beta)$ transus replaced the stress-relief anneal as the final thermal processing step in the coupon fabrication sequence.

\section{Irradiation}

The pressurized-water forced-circulation loops in the Idaho National Environmental Engineering Advanced Test Reactor Facility (ATR) operated at a $\mathrm{pH}_{25^{\circ} \mathrm{C}}$ of 10.2 with a hydrogen overpressure that maintained the oxygen content at $<20 \mathrm{ppb}$. The operating temperatures and fast-neutron $(>1 \mathrm{MeV}$ ) flux levels were relatively constant during each cycle, and from cycle to cycle between weighings. Nominal test temperatures of $274^{\circ} \mathrm{C}$, $310^{\circ} \mathrm{C}$, and $355^{\circ} \mathrm{C}$ combined with mean flux values between
$3 \times 10^{13}$ and $2 \times 10^{14} \mathrm{n} \mathrm{cm}^{-2} \mathrm{~s}^{-1}$ to provide a wide variety of irradiation conditions.

\section{Sample Preparation and Analysis}

This study comprises results from the work of several investigators using different TEM instruments over a period of more than ten years. For each $1 \mathrm{~mm}$-thick corrosion test coupon, electropolishing to perforation with $10 \%$ perchloric acid in methanol followed mechanical preparation of $3 \mathrm{~mm}$-diameter, 150 $\mu \mathrm{m}$-thick disks.

Structurally-dependent contrast in TEM images, and the corresponding energy dispersive X-ray spectroscopic (EDS) analyses that profiled $\mathrm{Fe}$ depletion jointly revealed regions of amorphous transformation. Simple manual measurements of photographic reproductions quantified the apparent widths of these zones. Selected area electron diffraction (SAD) patterns identified precipitate crystal structures, and confirmed the presence and extent of irradiation-induced amorphization. Chemical and structural analyses of several precipitates in each TEM disk were sometimes available.

\section{$\underline{\text { Results }}$}

Table I lists specimens whose microstruicture and irradiation history left partially amorphous Laves phase $\mathrm{Zr}(\mathrm{Fe}, \mathrm{Cr})_{2}$ precipitates. There were three other specimens with processing and exposure histories similar to the coupons in the table, but only totally amorphous precipitates were visible in the TEM images. In most instances, the model correctly predicted an amorphous-zone width greater than the apparent radius of the largest precipitate. One foil contained an amorphous structure whose minimum edgeto-center distance exceeded the prediction by a factor of two.

The table shows total-time averages of the flux and temperature for each specimen. Equation 4 predicted the amorphous-zone widths in the next-to-last column with these values. The actual exposure cycles lasted anywhere from 2 to 50 days, and the test records contain mean values for those intervals. Figure 1 shows cycle-to-cycle variation that is typical for the ATR. With those

\begin{tabular}{|c|c|c|c|c|c|c|c|c|c|c|c|}
\hline \multirow[t]{3}{*}{ Specimen } & \multirow[t]{3}{*}{ Anneal } & \multirow{3}{*}{$\begin{array}{c}\text { Precipitate } \\
\text { Structure }\end{array}$} & \multicolumn{4}{|c|}{ Irradiation History } & \multicolumn{5}{|c|}{ Amorphous Zone Width (nm) } \\
\hline & & & \multirow{2}{*}{$\begin{array}{c}\text { Mean } \\
\text { Temp }\left({ }^{\circ} \mathrm{C}\right)\end{array}$} & \multirow{2}{*}{$\begin{array}{l}\text { Time } \\
\text { (days) }\end{array}$} & \multirow{2}{*}{$\begin{array}{l}\text { Mean Flux } \\
\left(10^{14} \mathrm{n} \mathrm{cm}^{-2} \mathrm{~s}^{-1}\right)\end{array}$} & \multirow{2}{*}{$\begin{array}{c}\text { Fluence } \\
\left(10^{20} \mathrm{n} \mathrm{cm}^{-2}\right)\end{array}$} & \multicolumn{3}{|c|}{ Measured (arbitrary foil ID) } & \multicolumn{2}{|c|}{ Predicted } \\
\hline & & & & & & & a & $b$ & $c$ & Eq'n 4 & Eq'n 8 \\
\hline $1 \mathrm{~A} 033$ & $\alpha+$ ppte & hcp & 315.7 & 936 & 0.525 & 42.4 & 41 & & & 35 & 32 \\
\hline $9 D 043$ & $\alpha+$ ppte & hcp & 316.0 & 569 & 1.887 & 92.8 & 118 & 119 & 121 & 120 & 113 \\
\hline JAHL1 & $\alpha+$ ppte & hcp & 309.6 & 996 & 0.386 & 33.2 & 31 & 51 & & 27 & 22 \\
\hline $2 \mathrm{C} 264$ & $\alpha+$ ppte & hcp & 355.5 & 517 & 1.122 & 50.2 & 31 & 31 & 34 & 30 & 30 \\
\hline 100321 & $\alpha+\beta$ & $f \subset c$ & 355.5 & 517 & 1.122 & 50.2 & 36 & & & 30 & 30 \\
\hline
\end{tabular}
and similar cyclic data, Equation 8 yielded the cumulative values of $\delta$ that appear in the last column of Table I.

Table I Coupon Characteristics and $\mathrm{Zr}(\mathrm{Fe}, \mathrm{Cr})_{2}$ Amorphization 


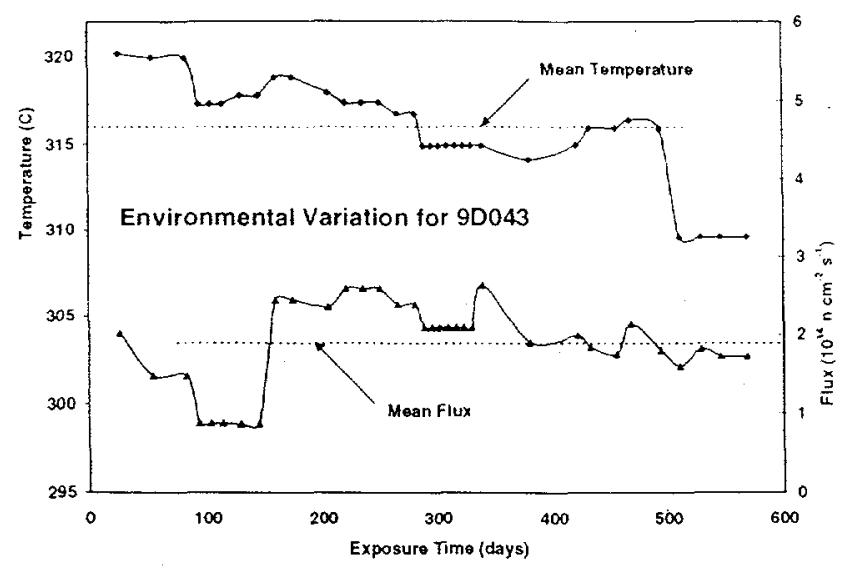

Figure 1: Variation of temperature and neutron flux during exposure of coupon 9D043 in the ATR. The dashed lines are averages over the total exposure time.

Amorphization measurements are subjective, and the precision depends strongly upon image magnification. print quality, and whether the intent of the original investigator was to optimize structural contrasts for zone-width delineation. The agreement between theory and observation was quite goot. The Discussion offers a rationale for expecting most measurements to fall at or above the prediction, and the closed symbols in Figure 2 show that this was generally true for the model with $\alpha$ as a timedependent variable.

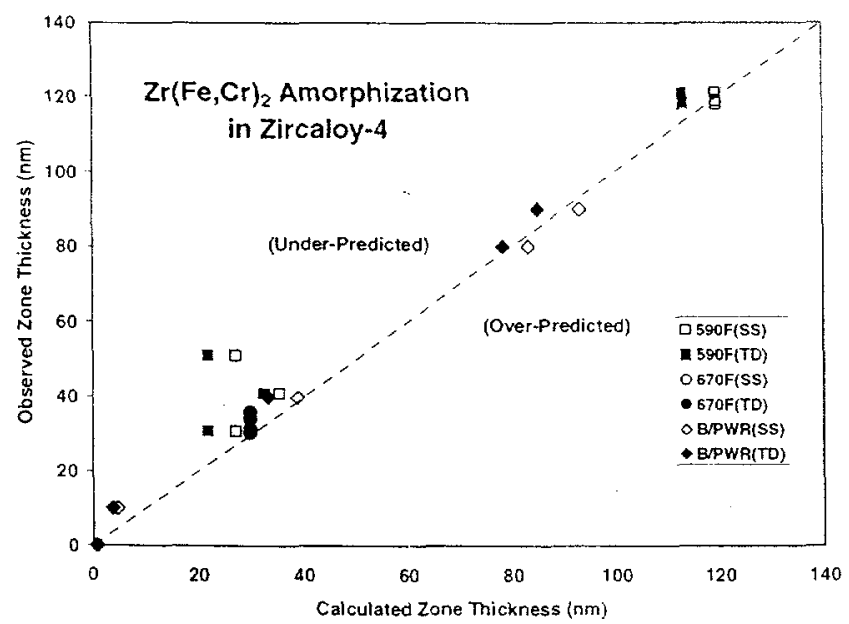

Figure 2: Predictions of the $\mathrm{Zr}(\mathrm{Fe}, \mathrm{Cr})$, amorphization model. Data from Table I. Open symbols. steady-state (Equation 4); closed symbols, time-dependent $\alpha$ (Equation 8 ). BWR and PWR data for Zircaloy-4 from Reference 18.

Most analytical electron microscopy (AEM) measurements reflected the nominal 2:1 ratio of $\mathrm{Fe}: \mathrm{Cr}$. but the $\mathrm{Fe}$ contents tended to be closer to 30-than 40 atom-percent. Quantitative measurements in the amorphous zones were even more difficult. but $\mathrm{Fe}: \mathrm{Cr}$ generally approached $0.3-0.5$. nominally 10 atompercent Fe, with no apparent dependence upon temperature.

Figure 3 is a bright-field image of the precipitate in foil ' $c$ ' from coupon 9D043. It is rectangular in shape. and the contrast is excellent. but is orientation with respect to the electron beam created a transition region where the lower part of the core appears 10 be visible through a partially-transparent amorphous zone.

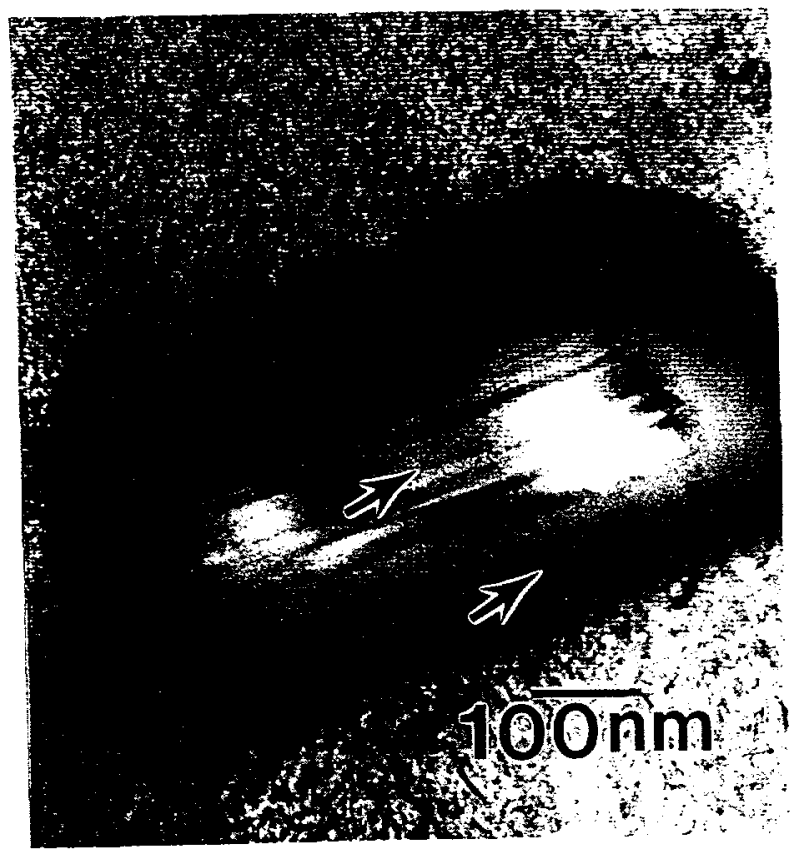

Figure 3: Partially amorphous $\mathrm{Zr}(\mathrm{Fe}, \mathrm{Cr})_{2}$ precipitate in foil ' $c$ from 9D043. The arrows mark locations of AEM analyses that contirmed loss of Fe to the matrix from the amorphous shell.

Figure 4 shows two more $\mathrm{Zr}(\mathrm{Fe} . \mathrm{Cr})$ 2 precipitates from 9D043. one totally amorphous and barely visible, at a magnification that was more typical for the measurements in Table 1.

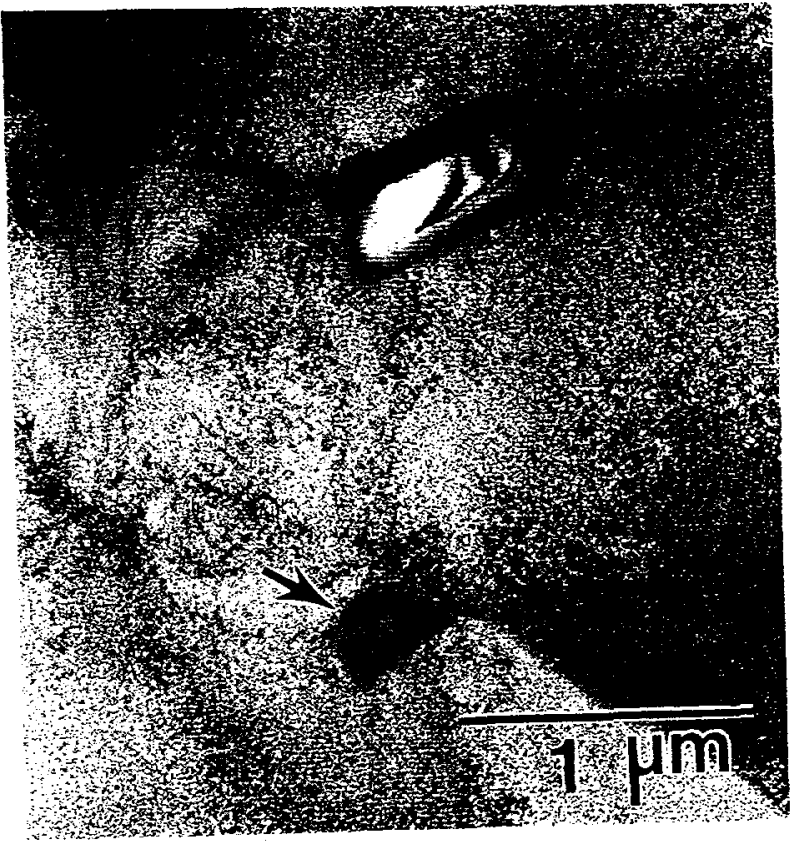

Figure 4: Partially and fully amorphous Zr(Fe.Cr): precipitates in toil 'b' from 9D043. The arrow indicates a small. torally amorphous spheroidal precipiate. 
Except in those rather common instances where electropolishing had preferentially dissolved the crystalline core and left the remains of an amorphous shell (Figure 5), it was never clear whether preparation of the specimen had sectioned a precipitate, or left it intact within the foil.

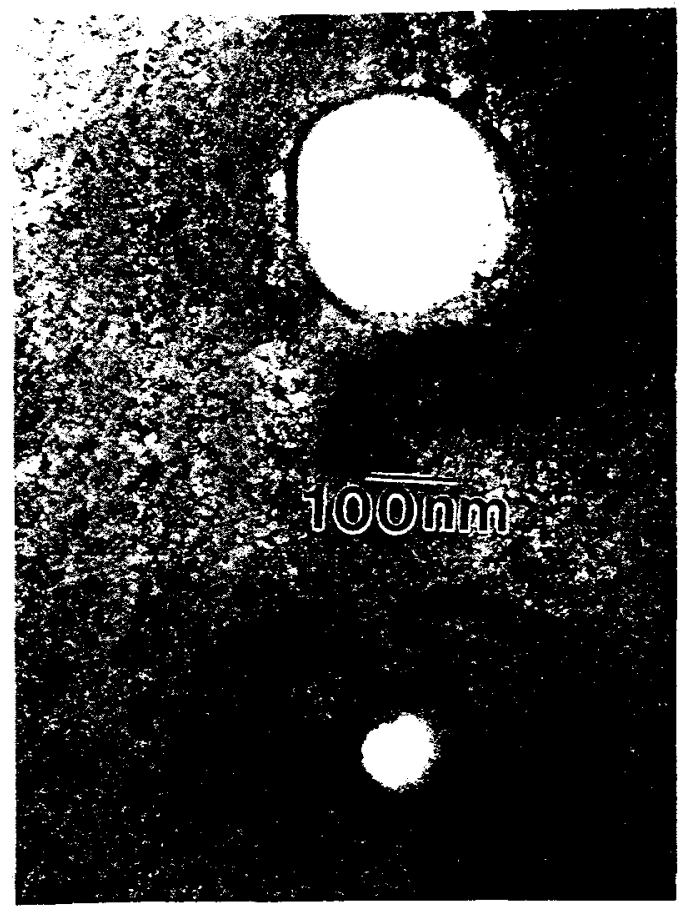

Figure 5: Examples of residual amorphous shells after electropolishing dissolved crystalline cores from partially amorphous $\mathrm{Zr}(\mathrm{Fe}, \mathrm{Cr})_{2}$ precipitates in Zircaloy-4.

Equation 10 predicts faster crystalline/amorphous boundary motion in smaller precipitates, and close examination of Figures 3 and 4 shows that the blocky precipitates both showed a tendency for slightly more rapid zone development where the radius of curvature was smaller at their narrow ends. The smallest dimension of the totally amorphous spheroidal precipitate in Figure 4 appears to be about $260 \mathrm{~nm}$, equivalent to an amorphouszone width of about $130 \mathrm{~nm}$ and slightly greater than the linearmodel values.

Table II lists the results of calculations using Equation 10 with the 9D043 flux and temperature conditions from Table I.

Table II Amorphization of Spherical Precipitates

\begin{tabular}{cccc}
\hline $\begin{array}{c}\text { Zone Width } \\
(\mathrm{nm})\end{array}$ & $\begin{array}{c}\text { Ppte Radius } \\
\mathrm{R}(\mathrm{nm})\end{array}$ & $\begin{array}{c}\text { Core Radius } \\
\mathrm{r}(\mathrm{nm})\end{array}$ & $\begin{array}{c}\text { Time } \\
\text { (days) }\end{array}$ \\
\hline & & & \\
119.7 & Large & $\mathrm{R}-119.7$ & $\mathbf{5 6 8 . 9}$ \\
119.7 & 500.0 & 380.3 & $\mathbf{5 4 2 . 8}$ \\
119.7 & 119.7 & 0.0 & $\mathbf{4 9 5 . 2}$ \\
& & & \\
$\mathbf{1 2 4 . 4}$ & 500.0 & 375.6 & 568.6 \\
$\mathbf{1 2 5 . 6}$ & 400.0 & 274.4 & 568.9 \\
$\mathbf{1 3 1 . 0}$ & 200.0 & 69.0 & 568.8 \\
$\mathbf{1 3 5 . 3}$ & 135.3 & 0.0 & 568.6 \\
\hline
\end{tabular}

For very large ' $R$ ', the result is the same as with Equation 4 since both use the steady-state approximation. The first three entries in the last column reflect a decreasing initial precipitate size as less time to reach a zone width of $120 \mathrm{~nm}$. The model predicts a $13 \%$ decrease in time for total amorphization relative to linear interfacial motion in this case. The inverse application of Equation 10 for the same conditions and actual total exposure time predicts a wider zone for smaller precipitates, with a $13 \%$ increase in the size of precipitate that could become completely amorphous.

\section{Discussion}

Since electrons that scatter from the beam as it passes through the foil form the bright-field TEM images, the amorphous zones of precipitates that lie totally within the foil should provide the most accurate results. If the shell is uniform as in Figure 6, the zone should appear to be of constant width, with indistinct contrast gradients at the interfaces, and reflect its actual size.

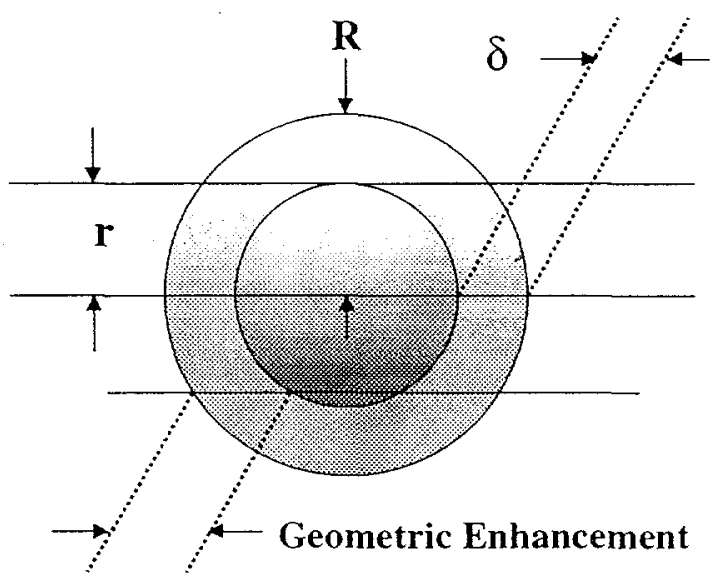

Figure 6: Schematic of partially amorphous spherical precipitate. Original radius ' $R$ ', crystalline-core radius ' $r$ ', amorphous-zone width $\delta=(R-r)$. Horizontal lines denote various planes of intersection with the foil surface.

At the opposite extreme, specimen preparation could leave a totally amorphous spherical segment, an "end cap" with a maximum thickness equal to the actual zone thickness $\delta$ that would appear to be a precipitate of radius $\delta_{\text {meas }}$. The amorphous particle in Figure 4 could be a small precipitate, or the polishing remnant from a larger one. For such an end cap,

$$
\begin{aligned}
& \delta_{\text {meas }}{ }^{2}+r^{2}=R^{2} \text { and } r=R-\delta \text {; thus } \\
& \delta_{\text {meas }} / \delta=\{(2 R / \delta)-1\}^{1 / 2} \text { for } R \geq \delta .
\end{aligned}
$$

Figure 7 is a graphical representation of this relationship that defines the theoretical range of measurements consistent with a single zone size. It suggests that the lower bound of all $\delta_{\text {meas }}$ values should provide the best estimate of $\delta$.

Variations in electrolytic polishing parameters can create artifacts during TEM thin-foil preparaton. Preferential attack of the precipitates, most commonly at one or more interfaces, generates images with uneven contrast as in Figure 3. Preferential attack of the matrix puts the precipitates in relief, and the resulting images 


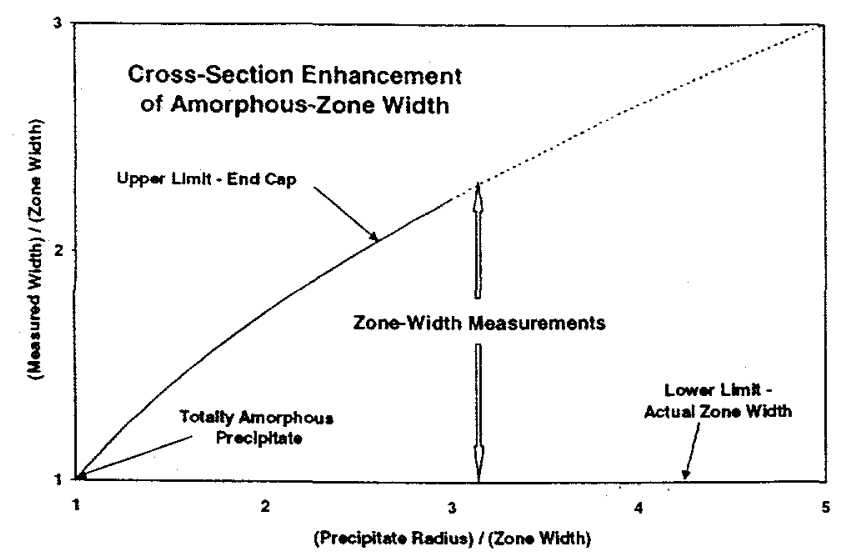

Figure 7: Theoretical bound to amorphous-zone measurements.

are totally dark with no visual evidence of either crystallinity or amorphization. Combining low-index orientation for uniformabsorption imaging with uniform polishing optimizes conditions for a clear boundary between the amorphous shell and the crystalline core.

The formation of non-planar surfaces by mechanical fragmentation and preferential electrochemical etching provides the simplest explanation for non-symmetrical zone widths in the micrograph of a single precipitate. These images are probably the least reliable source of amorphization data, since measurements of the minimum apparent zone width could easily fall below the true value.

Obtaining reliable and reproducible amorphization data is difficult. These new measurements are consistent with the model's original constants, and the accuracy of the equations probably would not benefit significantly from parameter optimization after this addition to the amorphization database.

The details of any contribution by precipitate amorphization to corrosion mechanisms remain elusive. Radial gradients in oxidation rates or electronic conductivity could change the effective size, rate of solute injection, degree of cathodic protection, and hydrogen-reduction characteristics of precipitates as the barrier layer advances past them into the matrix. The tendency for preferential electrochemical etching of crystalline cores raises a question as to whether the amorphous region is less chemically active, or simply less electronically conductive. The model assumes amorphization through structural excitation by the neutron flux. The corresponding elevation of molar free energy and loss of long-range order is more consistent with higher reactivity and lower conductivity for the amorphous shell.

\section{Conclusions}

The linear steady-state model is simple and accurate. Introducing time-dependence for ' $\alpha$ ' adds minor complexity, but should improve predictions of $\mathrm{Zr}(\mathrm{Fe}, \mathrm{Cr})_{2}$ amorphization when the neutron flux and temperature fluctuate significantly during irradiation. Acceleration of depletion-zone growth by a finite radius of curvature is not insignificant, and linking the model to a specific precipitate-size distribution is more precise in onedimensional spherical coordinates. The potential improvement in accuracy justifies the complexity of combining these two modifications, but in any form, the model provides unique information about the microstructural evolution of $\mathrm{Zr}(\mathrm{Fe}, \mathrm{Cr})_{2}$ precipitates in Zircaloy-4 as a function of time, temperature, and fast-neutron flux.

\section{Acknowledgements}

We are grateful to D.E. Harrison, J. Greggi, L.E. Thomas, J.M. McCarthy, V.P. Nordstrom, and N. Lewis, whose documentation of TEM analyses over the years made this evaluation possible. The US DOE sponsored all phases of this work through contracts and sub-contracts with the Westinghouse Electric Corporation, $\mathrm{GE}$, and Lockheed Martin Corporation.

\section{References}

1. R.W. Gilbert, M. Griffiths, and G.J.C. Carpenter, J. Nucl. Mater. 135 (1985) 265.

2. W.J.S. Yang, R.P. Tucker, B. Cheng, and R.B. Adamson, Proc. Workshop on Second Phase Particles and Matrix Properties of the Zircaloys, Erlangen, 1985.

3. M. Griffiths, R.W. Gilbert, and B.A. Cheadle, ibid.

4. F. Garzarolli and H. Stehle, IAEA STIPUB/721, International Atomic Energy Agency, Vienna (1987) p. 387.

5. F. Garzarolli, H. Stehle, and E. Steinberg, Proc. 11th Intl. Symp. on Zirconium in the Nuclear Industry, ASTM STP 1295 (1996) 12.

6. F. Garzarolli, P. Dewes, G. Maussner, and H.-H. Basso, Proc. 8 th Intl. Symp. on Zirconium in the Nuclear Industry, ASTM STP 1023 (1989) 641.

7. A.T. Motta and C. Lemaignan, J. Nucl. Mater. 195 (1992) 277.

8. M. Griffiths, R.W. Gilbert, and G.J.C. Carpenter, J. Nucl. Mater. 150 (1987) 53.

9. H.R. Peters and J.L. Harlow, Proc. 11th Intl. Symp. on Zirconium in the Nuclear Industry, ASTM STP 1295 (1996) 295.

10. W.J.S. Yang, J. Nucl. Mater. 158 (1988) 71.

11. B.-C. Cheng, R.M. Kruger, and R.B. Adamson, Proc. 10th Intl. Symp. on Zirconium in the Nuclear Industry, ASTM STP 1245 (1994) 400.

12. B.-C. Cheng and R.B. Adamson, Proc. 7 th Intl. Symp. on Zirconium in the Nuclear Industry, ASTM STP 939 (1987) 387.

13. D.F. Taylor, J. Nucl. Mater. 184 (1991) 65.

14. A.W. Urquhart, D.A. Vermilyea, and W.A. Rocco, J. Electrochem. Soc. 125 (1978) 199.

15. Y. Ito and T. Furuya, Proc. 11 th Intl. Symp. on Zirconium in the Nuclear Industry, ASTM STP 1295 (1996) 163. 
16. T. Isobe, T. Murai, and Y. Mae, Proc. 11th Intl. Symp. on Zirconium in the Nuclear Industry, ASTM STP 1295 (1996) 203.

17. Ph. Bossis, G. Lelievre, P. Barberis, X. Iltis, and F. Lefebvre, "Multi-Scale Characterization of the Metal-Oxide Interface of Zirconium Alloys," presented at the 12th Intl. Symp. on Zirconium in the Nuclear Industry, Toronto, June 1998.
18. D.F. Taylor, H.R. Peters, and W.J.S. Yang, “A Simple Kinetic Model of Zircaloy $\mathrm{Zr}(\mathrm{Fe}, \mathrm{Cr})_{2}$ Precipitate Amorphization during Neutron Irradiation," submitted to J. Nucl. Mater. November 1998. 